\title{
Training Emergency Medicine Residents-the Skill of Endotracheal Intubation: Comparison of Human Cadavers vs Mannequins
}

\author{
1 Josh Rothstein, ${ }^{2}$ Jennifer Gullo, ${ }^{3}$ Lee Cuningham, ${ }^{4}$ Peter Murphy, ${ }^{5}$ Mark Sochor
}

\begin{abstract}
Introduction and objectives: There are multiple approaches to teach residents the skill of endotracheal intubation, including classroom teaching, cadaveric specimens, and simulation mannequins. The hypothesis of our study is training in the technique of intubation is equally mastered (resident confidence and competency) in training on human cadavers or simulation mannequins.
\end{abstract}

Materials and methods: Emergency medicine interns were asked to voluntarily enroll in the study prior to the beginning of intern year and randomized into two groups. The first group practiced intubation using mannequins. The second group practiced intubation using human cadavers. Both groups were given the same brief introductory lecture on the basics of endotracheal intubation. One week later, all the interns returned and attempted to intubate cadavers and mannequins. Competency assessment was based on the number of successful intubations, number of attempts, and use of adjunctive techniques. Interns were also surveyed after their anesthesia rotation with a Likert scale on confidence of being able to perform intubation.

Results: The overall average number of attempts was 1.67 in the mannequin group and 1.85 in the cadaver group. Mannequin trained interns had a total of 24 poor techniques noted over the 2 years. The cadaver trained group had a total of 35 poor techniques over the 2 years. Adjunct use was nearly identical in the two groups. Intubation success rate during anesthesia rotation and preparation ratings were nearly identical in the two groups. However, the cadaver-trained group reported feeling slightly more confident.

Conclusion: Overall, mannequins require fewer attempts to intubate and being mannequin trained results in fewer attempts. Adjunct use is independent of training type. The mannequintrained group had less episodes of poor technique than the

\footnotetext{
${ }^{1}$ Chief Resident, ${ }^{2}$ Emergency Medicine Physician

${ }^{3,4}$ Resident, ${ }^{5}$ Associate Professor, Research Director

${ }^{1-3}$ Department of Emergency Medicine, University of Virginia VA, USA

${ }^{4}$ Department of Family Medicine, University of Virginia, VA, USA

${ }^{5}$ Department of Emergency Medicine, Research Office; University of Virginia, VA, USA
}

Corresponding Author: Josh Rothstein, Department of Emergency Medicine, University of Virginia, VA, USA, Phone: 14349248485, e-mail: jdr8s@virginia.edu cadaver-trained group. A mannequin training appears to be equivalent or better than cadaveric training for securing an airway, although cadaver trained interns reported slightly more confidence.

Keywords: Intubation, Emergency medicine residency, Graduate medical education, Emergency medicine education, Intubation training.

How to cite this article: Rothstein J, Gullo J, Cuningham L, Murphy P, Sochor M. Training Emergency Medicine Residentsthe Skill of Endotracheal Intubation: Comparison of Human Cadavers vs Mannequins. Panam J Trauma Crit Care Emerg Surg 2014;3(1):8-10.

Source of support: Nil

Conflict of interest: None

\section{RESUMEN}

Existen múltiples enfoques para enseñar a los residentes de la habilidad de la intubación endotraqueal, incluyendo enseñanza en el aula, los especímenes cadavéricos, y la simulación maniquíes. La hipótesis de nuestro estudio es la formación en el técnica de la intubación se domina por igual (confianza residente y la competencia) en la formación de cadáveres o de simulación humanos maniquíes.

Palabras claves: Intubación, La educación médica graduamte, Formación residente, Medicina de emergencia, Residencia de Medicina de emergencia.

\section{INTRODUCTION}

The Society for Academic Emergency Medicine states that 'emergency physicians possess a wide range of skills to treat injuries and illnesses and perform many interventions including but not limited to resuscitative procedures and trauma stabilization in patients of all ages.' Competency in resuscitation and stabilization is gained through skills learned during residency training. According to the Accreditation Council for Graduate Medical Education guidelines (ACGME), emergency medicine residents 'are expected to competently perform therapeutic procedures and emergency stabilization.' These same guidelines require that residents perform 35 intubations during their training. ${ }^{1}$

There are multiple approaches to teach residents the skill of endotracheal intubation, including classroom teaching, cadaveric specimens, and simulation mannequins. One of 
the concerns with using simulators is which style is more effective not only in skill acquisition, but retention and level of comfort. Steadman et $\mathrm{al}^{2}$ compared simulation-based learning to problem-based learning (PBL) and found that students randomized to a clinical scenario on the simulator excelled compared with the PBL group. Two similar studies compared didactic teaching to simulation in both emergency medicine and obstetrics/gynecology residency and found that simulation was superior. ${ }^{3,4}$ Over the years, a number of studies have proven the effectiveness of mannequins and simulators as a teaching tool, not only in medical knowledge but also in procedure comfort and learning assessment. ${ }^{5,6}$ An equal number of studies have validated the use of cadavers as a means of teaching procedures, including endotracheal intubation, to medical students and residents. ${ }^{7-10}$

To our knowledge, there has been only one study that compared endotracheal intubation using cadavers to mannequins. ${ }^{11}$ However, this study did not address resident competency or confidence but rather participant preference and realism. The hypothesis of our study is training in the technique of intubation is equally mastered (resident confidence and competency) using human cadavers or simulation mannequins. Our hope is that the data from this study will allow us to evaluate which method of teaching endotracheal intubation is the most effective and subsequently reevaluate the emergency medicine resident curriculum and possibly alter it based on our findings.

\section{MATERIALS AND METHODS OF RESEARCH}

Emergency medicine residents from the class of 2014 and 2015 (currently there are 10 residents per class) were asked to voluntarily enroll in the study prior to the beginning of intern year in July 2011 and July 2012. The class was given the same brief introductory lecture on the basics of endotracheal intubation and then randomized into two groups.

The first group practiced intubation using mannequins in a simulation center. The second group practiced intubation using human cadavers. Each group had access to a gum bougie (a long, stiff rod used as an adjunctive measure during difficult intubations). Additionally, each group learned how to intubate a cadaver or mannequin in a cervical spine collar (C-collar). A C-collar is used on trauma patients to stabilize the cervical spine, however, it does create a difficult airway in the event that a trauma patient requires intubation.

One week later, all the residents returned and attempted to intubate a mix of cadavers and mannequins. Competency assessment was based on the number of successful intubations, number of attempts, and use of adjunctive techniques. Adjunctive techniques were defined as use of the bougie, cricoid pressure, cervical collar removal, and/or c-spine stabilization by an assistant. This was accomplished through the use of an evaluation form completed by study administrators. In addition, each resident was surveyed to record their comfort level when intubating as well as if they felt their respective training technique prepared them for the test. As follow-up, each resident was contacted after they completed their required anesthesiology rotation. They were given a voluntary survey, which ascertained how many intubations they performed both successfully and unsuccessfully, if they felt comfortable doing so and if they felt their respective training technique prepared them adequately. Emergency medicine interns were asked to voluntarily enroll in the study prior to the beginning of intern year and randomized into two groups. The first group practiced intubation using mannequins. The second group practiced intubation using human cadavers. Both groups were given the same brief introductory lecture on the basics of endotracheal intubation. One week later, all the interns returned and attempted to intubate cadavers and mannequins. Competency assessment was based on the number of successful intubations, number of attempts, and use of adjunctive techniques.

\section{RESULTS}

Interns trained on mannequins took an average of 1.225 attempts to successfully intubate a mannequin and average of 2.125 attempts to successfully intubate cadavers on repeat competency assessment. Those trained on cadavers averaged 1.125 attempt to intubate mannequins and 2.575 attempts to intubate cadavers. The overall average number of attempts was 1.67 in the mannequin group and 1.85 in the cadaver group. The only group that did not use any adjuncts was the mannequin group when intubating mannequins. The cadaver trained group used boogies and c spine help when intubating the mannequins. Both groups used bougie, cricoid pressure, and c-spine help to intubate cadavers. One person in the mannequin trained group also used suction as an adjunct to intubate a cadaver. Mannequin trained interns had a total of 24 poor techniques noted over the 2 years with 8 on the mannequin and 16 on the cadaver. The cadaver trained group had a total of 35 poor techniques over the 2 year period with 20 recorded on the mannequins and 15 on the cadavers.

In the postanesthesia surveys, residents trained on cadavers were successful in intubating humans $87 \%$ of the time and residents trained on mannequins were successful $86 \%$ of the time. On a scale from 1 to 7 , residents in both groups had an identical average rating of how well they felt prepared of 6.14. The average comfort in intubating rating was 5.86 on a scale of 1 to 7 in the cadaver group and 5.71 in the mannequin group. 


\section{DISCUSSION}

There are a number of important limitations to this study. The study subjects had a broad variety of procedural experience prior to study enrolment. The subjects' pre-existing experience varied from little to no hands-on patient care experience to multiple years of EMS practice, dedicated medical school anesthesiology rotations, and more. This was not controlled for and considering the small size of our cohort this is a potential confounder.

This study was also carried out over multiple years and each year different evaluators were used. Objective criteria for good and poor technique during assessment were discussed with each investigator but interobserver variability was not formally addressed and may have affected results.

Finally, the same investigators were present for both the training phase and the assessment phase and could not be blinded to which type of training each intern received.

\section{CONCLUSION}

Overall, mannequins require fewer attempts to intubate and being mannequin-trained results in fewer attempts. Adjunct use is independent of training type. However, mannequin trained interns did not require any adjuncts when intubating mannequins. The mannequin trained group had fewer episodes of poor technique than the cadaver-trained group.

In a postanesthesia rotation survey, both groups felt equally prepared to intubate humans; however, the cadaver group reported a slightly increased confidence level compared with the mannequin group. The success rates were nearly identical in the two groups (87-86\%).

\section{REFERENCES}

1. USA. Accreditation Council for Graduate Medical Education. AC GME Program Requirements for Graduate Medical
Education in Emergency Medicine. N.p. ACGME, and Print. Available at: http://www.acgme.org/acgmeweb/Portals/0/ PFAssets/2013-PR-FAQ-PIF/110_emergency_medicine_ 07012013.pdf.

2. Steadman, Randolph H, Coates WC, Huang YM, Matevosian R, Larmon BR, McCullough L, Ariel D. 'Simulation-based training is superior to problem-based learning for the acquisition of critical assessment and management skills.' Crit Care Med 2006;34(1):151-157.

3. Daniels K, Arafeh J, Clark A, Waller S, Druzin M, Chueh J. 'Prospective randomized trial of simulation versus didactic teaching for obstetrical emergencies.' Simul Health 2010; 5(1):40-45.

4. Wang, Ernest E, Beaumont J, Kharasch M, Vozenilek JA. 'Resident response to integration of simulation-based education into emergency medicine conference. Acad Emerg Med 2008; 15(11):1207-1210.

5. Okuda, Yasuharu, Bryson EO, DeMaria S, Jacobson L, Quinones J, Shen B, Levine AI. The utility of simulation in medical education: what is the evidence? M Sinai J Med 2009;76(4):330-343.

6. Cooke JM, Larsen J, Hamstra SJ, Andreatta PB. Simulation enhances resident confidence in critical care and procedural skills. Fam Med 2008;40(3):165-167.

7. Custalow, Catherine B, Kline JA, Marx JA, Baylor MR. Emergency department resuscitative procedures: animal laboratory training improves procedural competency and speed. Acad Emerg Med 2002;9(6):575-586.

8. Oxentenko AS, Ebbert JO, Ward LE, Pankratz VS, Wood KE. A multidimensional workshop using human cadavers to teach bedside procedures. Teach Learn Med 2003;15(2):127-130.

9. Tabas JA, Rosenson J, Price DD, Rohde D, Baird CH, Dhillon $\mathrm{N}$. A comprehensive, unembalmed cadaver-based course in advanced emergency procedures for medical students. Acad Emerg Med 2005;12(8):782-785.

10. Weaver ME, Kyrouac JP, Frank S, Rabinovich S. A cadaver workshop to teach medical procedures. Med Edu 1986; 20(5):407-409.

11. Yang JH, Kim YM, Chung HS, Cho J, Lee HM, Kang GH, Kim EC, Lim T, Cho YS. Comparison of four manikins and fresh frozen cadaver models for direct laryngoscopic orotracheal intubation training. Emerg Med J 2010;27(1): 13-16. 